\title{
Long Haul Trucker Dies After Striking an Embankment at the End of an Interstate Highway Off-Ramp
}

\author{
Incident Number: 05KY074
}

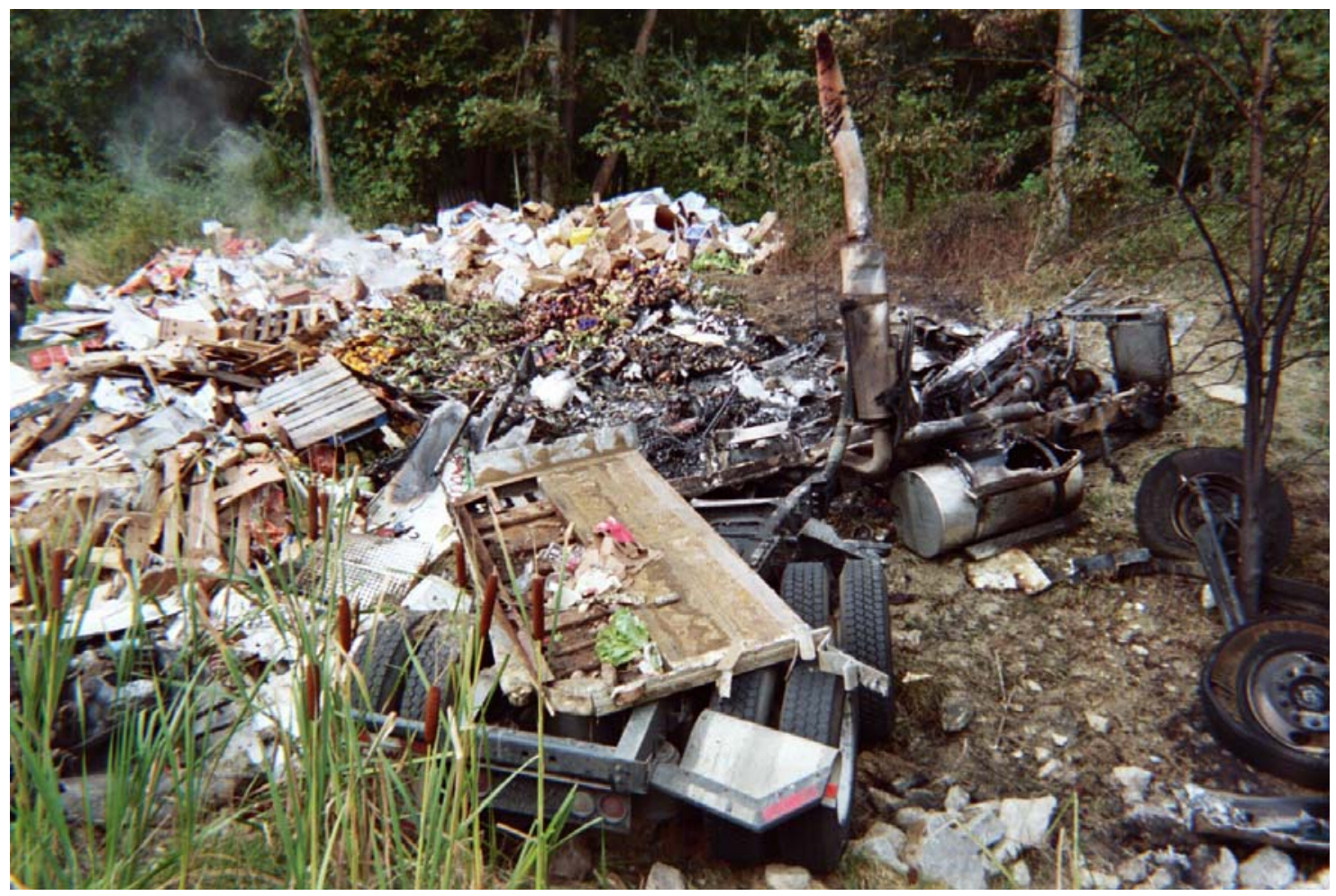

Picture of hillside with debris from semi-tractor trailer crash.

(Photo courtesy of private company)

Kentucky Fatality Assessment and Control Evaluation Progran Kentucky Injury Prevention and Research Center 333 Waller Avenue Suite 206

Lexington, Kentucky 40504

Phone: 859-323-2981

Fax: 859-257-3909

www.kiprc.uky.edu

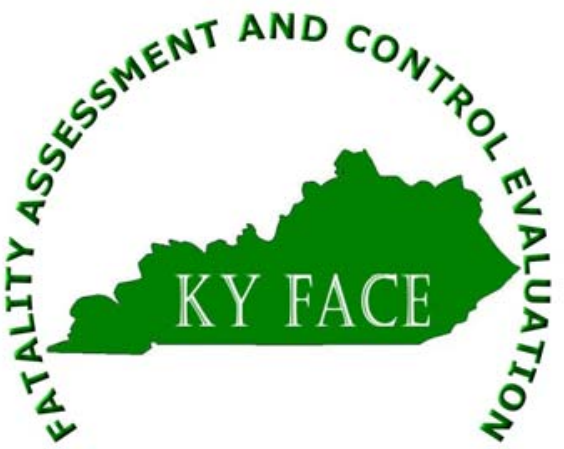




\title{
Kentucky Fatality Assessment and Control Evaluation (FACE) Program Incident Number: 05KY074 \\ Release Date: $\quad$ May 2, 2007 \\ Subject:

\author{
Long Haul Trucker Dies After Striking an Embankment \\ at the End of an Interstate Highway Off-Ramp
}

\begin{abstract}
Summary
In the fall of year 2005, at 12:40 AM, a 47-year-old male semi-truck driver began his delivery route hauling a refrigerated trailer loaded with 23,000 pounds of produce. His first delivery was approximately 265 miles away. After two hours and twenty minutes, he exited the interstate 23 miles from the start of his route. At the end of the exit ramp he attempted to turn right onto a 4lane highway. He missed the turn and drove straight across the highway through a guardrail; the truck became airborne, and crashed into an embankment exploding into flames. An unidentified motorist driving behind the semi called emergency response services. Local police and fire departments arrived at the scene and discovered the cab and trailer burning. The coroner arrived while the firefighters extinguished the blaze. After extinguishing the fire, emergency personnel removed the driver's body and the coroner declared the driver dead at the scene. The death certificate stated the cause of death was multiple blunt force trauma/motor vehicle accident, and that carbon monoxide possibly contributed to death. Toxicology test results showed the driver had a $0.6 \%$ blood level of cocaine, a presumptive presence of benzodiazepine, and a carbon monoxide level of $38 \%$ at the time of the crash.
\end{abstract}

Following are recommendations to prevent similar incidents from occurring:

Recommendation No. 1: A "reasonable suspicion" drug testing policy should be implemented and enforced by the company if a trucker is suspected to be under the influence of drugs. The reasonable suspicion testing policy should include drug testing and the suspension of the trucker until the results of the tests are known.

Recommendation No. 2: Comprehensive new-hire prescreening and after-hire random drug testing policies should be implemented and enforced for substance abuse

Recommendation No. 3: A statewide database containing commercial driver positive drug/ alcohol test results should be identified.

\section{Background}

The Kentucky Fatality Assessment and Control Evaluation (FACE) program conducted interviews with the local coroner, police, an environmental clean-up and towing company, a toxicologist, and a family member. The employer declined to participate in FACE's incident evaluation. 
The driver had been employed by the company for approximately six months and was an owneroperator for 21 years until March, 2005, when he was hired to drive as an employee for a hauling company. He drove day routes until May, 2005, when a long haul trucker position became available at one of the company's subsidiaries. His new job required him to begin his work shift at midnight, and leave the loading dock usually one to two hours later. His job duties during that two-hour time span were unknown. He drove a fixed route three times a week that required two days each to complete. The decedent drove a different semi each trip and worked approximately 60 hours a week driving. On his time off between routes, he was often asked to load trucks.

The company's profile on the Federal Motor Carrier Safety website described the company as a long distance hauler of general freight, fresh produce, and refrigerated food, which employed approximately 60 drivers. According to the police report, the semi tractor trailer was 48 feet long, was manufactured in 2004, and had a gross vehicle weight of 80,000 pounds. The coroner stated the semi was equipped with a global positioning system (GPS) device and a data recording box.

\section{Investigation}

In the fall of 2005, at 12:40 AM, a 47-year-old male long haul trucker drove a refrigerated trailer loaded with 23,000 pounds of produce, away from a distributor's warehouse loading dock. He was beginning the usual two day long route that he completed three times each week. His first destination was approximately 265 miles away and should have taken him six hours to reach after leaving the loading dock. After two hours and twenty minutes, the driver was approximately 23 miles away from the origination point. It is unknown what he was doing in that period. While en route west, he exited off the interstate 23 miles from the warehouse. At the end of the exit ramp, he attempted to turn right onto a four-lane highway, but instead drove straight across the highway through a guardrail, became airborne, and crashed into an embankment. It was estimated by the police that the truck was traveling approximately 60-65 miles per hour. The cab exploded into flames and the front axle of the cab broke loose. An unidentified motorist driving behind the semi called emergency medical services. Local police and fire departments were contacted at 3:01 AM, arrived at the scene at 3:07 AM, and found the semi and the trailer in flames. The police called a local towing company and the local coroner to the scene. While the fire department extinguished the fire, three employees from the towing company arrived at the scene as did the coroner.

On impact, the truck cab broke apart causing the mattress in the sleeper to fall forward onto the trucker, the cab to collapse onto the mattress, and the refrigeration unit of the trailer to collapse on top of the cab. The impact also caused the produce to spill from the trailer onto the ground and burn. The front axle of the semi was found nearby against a tree. A fire fighter found the burned trucker's body on the door frame underneath the mattress. Because of the steepness of the terrain, and the extent of damage to the semi and trailer, the towing company assisted the fire department in extracting the driver's body from the wreckage. A towing company employee used the tow truck to move the wreckage off the driver's body, then assisted two firefighters in removing the driver's body from the cab. The coroner declared the trucker dead at the scene. 
Police conducted a license plate check of the tractor, then contacted the employer and informed them of the motor vehicle collision involving a fatality. The coroner spoke to a company representative and discussed how to obtain dental records for the semi driver. Dental records were obtained from the family, and an identification of the body was made by the state medical examiner. Toxicology tests were conducted on the trucker and results showed he had a $0.6 \%$ blood level of cocaine, a presumptive presence of benzodiazepine, and a carbon monoxide level of $38 \%$ blood at the time of death.

During the coroner's and police investigations of the crash, the truck's GPS was found to be nonfunctional and the data recorder was burned and unusable in the crash. It is unknown if the GPS was functional before the crash. There were no weigh scales between the origination point of the route and the ramp where the semi driver exited. There were skid marks at the end of the ramp indicating the driver used brakes and had turned the steering wheel to the right. It is unknown why the driver took the exit ramp off the interstate. There were no driver facilities at that exit.

\section{Cause of Death}

The Death Certificate stated the cause of death as "multiple blunt force trauma/ motor vehicle accident/ carbon monoxide possibly contributed to death of subject”.

\section{Recommendations and Discussions}

Recommendation No. 1: A “reasonable suspicion” drug testing policy should be implemented and enforced by the company if a trucker is suspected to be under the influence of drugs. The reasonable suspicion testing policy should include drug testing and the suspension of the trucker until the results of the tests are known.

49 CFR 382.307(a) and 49 CFR 382.307(b) state that an employer who suspects that a driver is engaged in substance abuse is required to have the driver undergo alcohol and/or drug testing. Fleet supervisors should be trained to recognize signs of employee substance abuse and receive company authorization to have a driver submit to reasonable suspicion drug/ alcohol testing if he/she exhibits symptoms of substance abuse.

Recommendation No. 2: Comprehensive expanded new-hire prescreening and after-hire random drug/ alcohol testing policies should be implemented and enforced for substance abuse.

49 CFR 382.301 requires employers to perform pre-employment screening for controlled substance abuse on every new driver hired. Currently 49 CFR §40.85 requires companies to perform a five panel limited drug screen urine test for marijuana, cocaine, opiates, phencyclidine, and amphetamines performed prior to hiring new drivers. The Kentucky Transportation Cabinet should require companies to perform expanded drug testing separate from the Federal Department of Transportation's panel that might include drugs such as barbiturates, benzodiazepines, depressants, ecstasy, methadone, methamphetamines, oxycodone, tricyclic antidepressants, and other currently popular recreational drugs. By performing this separate drug panel, companies can better screen applicants and understand substance abuse; for example, the 
driver in this case tested positive for presumptive presence of benzodiazepine, a depressant. According to 49 CFR 382.305(b)(2), employers are required to annually test 50\% of company drivers for controlled substances. Companies should extend this policy and implement a policy of randomly testing all new hires for substance abuse within the first six months of employment.

Recommendation No. 3: A statewide database containing commercial driver positive drug/ alcohol test results should be identified.

In 2006, North Carolina instituted a law which requires employers to report all positive drug and alcohol tests of CDL drivers to the state's Division of Motor Vehicles. Those results are kept on record for two years. When performing background checks on potential drivers, employers in North Carolina can verify within the state whether or not the candidate tested positive for drugs / alcohol in the previous two years.

Kentucky should adopt a similar law and identify a center to house positive drug test results for all commercial driver's license (CDL) holders and applicants. Testing labs and employers should be required to report all positive drug and alcohol test results to the center. Positive test results should be cross-referenced by employee social security number and CDL number. Data should include, but not be limited to, results for drug and alcohol tests pre-employment, after 6 month of employment, random tests during employment, and post-accident tests. State law should ensure employers' access to the database to determine if the trucker had prior positive drug/ alcohol results prior to employment. All information should be confidential and released only to potential employers under rigid confidentiality guidelines and procedures.

\section{Keywords}

Semi-tractor trailer

Substance abuse

Trucker

\section{References}

http://www.fmcsa.dot.gov/safety-security/safety-initiatives/drugs/drug-guidelines.pdf

49 CFR 382.307(a)

49 CFR 382.307(b)

49 CFR 382.301

49 CFR 382.305(b)(2)

49 CFR Part 40, Subpart G

\section{Acknowledgements}

Kentucky Vehicle Enforcement

Local coroner

Local deputy coroner

Local police

Several professional semi drivers 
Several distribution companies

Towing company

Toxicologist

The Kentucky Fatality Assessment \& Control Evaluation Program (FACE) is funded by a grant from the Centers for Disease Control and the National Institute of Safety and Health. The purpose of FACE is to aid in the research and prevention of occupational fatalities by evaluating events leading to, during, and after a work related fatality. Recommendations are made to help employers and employees to have a safer work environment. For more information about FACE and KIPRC, please visit our website at: www.kiprc.uky.edu 


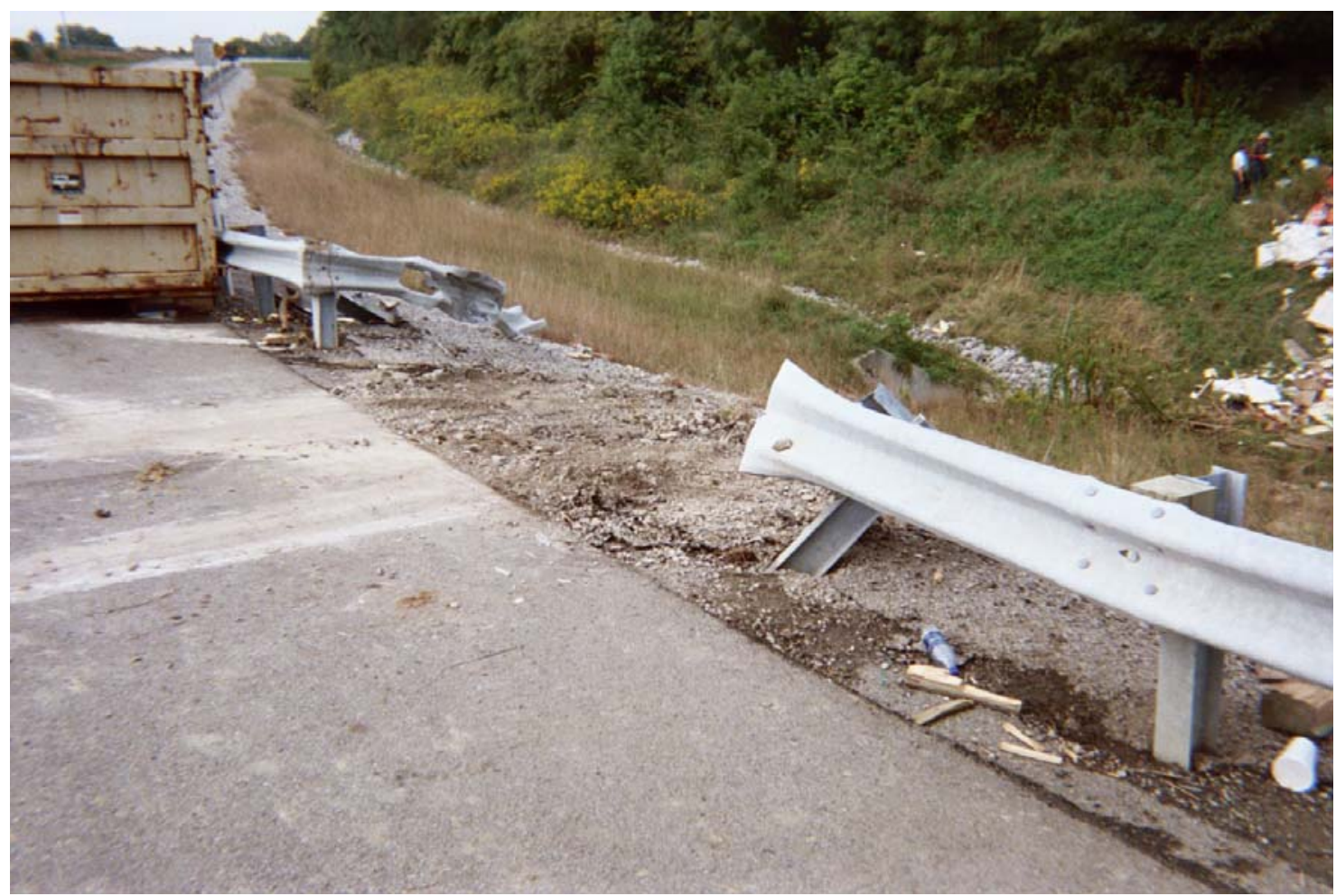

Area where semi went through guardrail.

(Photo courtesy of private company) 


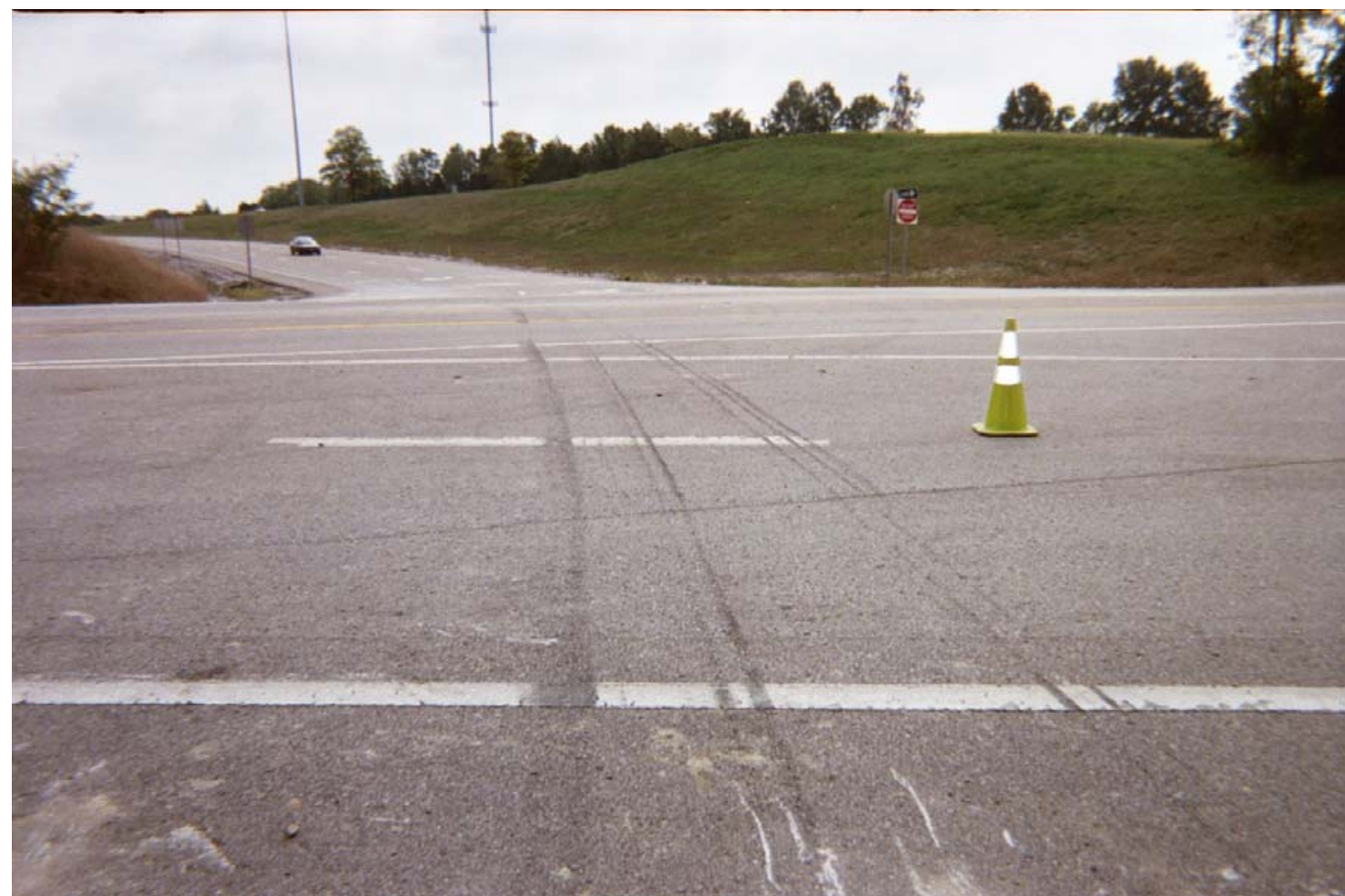

Skid marks on pavement caused by semi.

(Photo courtesy of private company) 